\title{
DEPARTMENT OF CHEMICAL TECHNOLOGY, UNIVERSITY OF BOMBAY
}

$\mathrm{T}$ HE Department of Chemical Technology of the University of Bombay has just celebrated its silver jubilee, and it is thus an opportune time to review briefly the development of this Department and its impact on Indian industries. Its foundation may be largely attributed to the vision and enthusiasm of Sir M. Visvesvaraya, who, as chairman of a Government of India committee, recommended as long ago as 1921 that a faculty of technology be instituted in the University of Bombay and that a College of Technology be established in Bombay City. It is probable that the practical difficulties associated with so large a scheme delayed its fulfilment, for it was not until 1930 that the matter was raised again in a more modest way, with the result that in 1934 the University started two new two-year courses, one in textile chemistry and the other in chemical engineering, to each of which twenty chemistry graduates might be admitted annually. The choice of subjects was a wise one : chemical engineering for its general applicability to all industries, and textile chemistry because of its value to the immense cotton industry of the Bombay Presidency. The first graduates were well received by industry, and the demand soon became far greater than the supply.

Moreover, many private individuals and associations, seeing that this was the beginning of a new era in industrial development, made handsome contributions for the endowment of chairs and readerships, or for the establishment and equipment of specialized laboratories. These have amounted so far to $£ 280,000$, and in conjunction with large government grants have made possible the erection on a 14-acre site of a group of laboratories of the most modern type on a unit basis, which allows extension or subdivision with a minimum of disturbance. Special features are the large quantity of small-scale plant and high-class instruments intended mainly for research work. There are a well-equipped workshop and a spacious drawing office in which all students have to work, and the library contains about 8,000 modern technical works and more than 200 periodicals to which readers have free access.

The two sections with which the Department started were originally housed in part of the Royal Institute of Science, which gave little room for expansion; but as soon as the success of the projeet was assured, preparations were made to build the new laboratories and to add more sections to the Department. Starting in 1943 when the laboratories were ready, new branches were gradually added, and there are now seven two-year courses of study open to chemistry graduates which lead to the degree of B.Sc. (Tech.). These are textile chemistry, and the technology of pharmaceuticals and fine chemicals, food, intermediates and dyes, oils, fats and waxes, plastics, and pigments, paints and varnishes. Chemical engineering is now a four-year course, starting from intermediate, for which the degree of B.Chem.E. is awarded, and there is also a three-year degree course from intermediate in pharmacy. In addition, emphasis is laid on research and work for higher degrees, and there are now 125 postgraduate students out of a total of about 525. Members of the Department have published in all more than 700 scientific notes, articles and papers, mostly on experimental work conducted in the laboratories. The Department also acts as a test house for the textile industry and undertakes sampling, analysis, the investigation of technical difficulties and more comprehensive schemes of industrial research for outside bodies.

The number of students has increased in a remarkable manner. Starting with 109 admitted during the first five years, it rose to 380 ten years later, and during the past four years it has been 785 . The proportion taking a degree is very high, more than 1,500 of the 1,700 admitted having been successful. These graduates are much sought after; up to the end of 1957, the last year for which detailed figures are available, 762 were engaged in the manufacturing industry out of a total of 1,316 .

Unfortunately, this healthy expansion is threatened by circumstances which must already be a source of anxiety to the authorities-the almost world-wide problem of staff. In Bombay the chairs of textile chemistry, food technology and chemical engineering are all vacant, and in the last-mentioned section one readership is vacant and one lecturer is on study leave, leaving one reader and a temporary lecturer to deal with a four-year course to which forty-five or even more students are admitted annually. It is evident that adequate teaching of the wide range of subjects contained in the syllabus cannot be main. tained without a large increase of staff. Other sections are suffering in the same way, although to a smaller extent, and the trouble has been mitigated slightly by members of the staff of other institutions, seventeen of whom are generously helping by giving part-time assistance. It would seem that a satisfactory state of affairs will not be reached until the Department's own graduates and those of similar establishments have increased in numbers and experience to such an extent that the small percentage who take up teaching (augmented perhaps by higher salaries) will be sufficient to provide an adequate staff.

The effect of the introduction of 1,500 trained scientists with an acquaintance with industrial conditions and a specialist knowledge of certain technical operations into the country, followed by more than 150 every year, cannot fail to exert a profound influence on the economy of Bombay and indeed of the whole of India. When it is considered that a large proportion of these men have, in addition, a research outlook which may lead to important improvements, it is difficult to form any estimate as to the changes which may result. It suffices to say that these changes can be only for the good and likely to give the utmost satisfaction to all who so wisely gave their time and their money to further the cause of technical education.
H. E. WATSON 